\title{
LOS TRABAJADORES DE LA MADERA EN ARGENTINA, 1909-1910. CLASE, OFICIO, RELACIONES ÉTNICAS Y CULTURAS POLÍTICAS
}

\author{
The woodworkers of Argentina, 1909-1910. \\ Class, craft, ethnic relations and political cultures
}

\author{
Walter L. Koppmann \\ Instituto de Historia Argentina y Americana \\ Dr. Emilio Ravignani \\ CONICET / Universidad de Buenos Aires, \\ Argentina
}

\begin{abstract}
Resumen: El artículo aborda la conflictividad social en la ciudad de Buenos Aires entre 1909 y 1910, poniendo el foco sobre los trabajadores de la industria de la madera y el mueble. A través del estudio de caso, se abordan las formas de lucha y de organización, la incidencia del oficio artesanal en un medio escasamente mecanizado, la intervención de las corrientes de izquierda y el lugar que ocupaban las relaciones étnicas, en particular la inmigración judía, en el ramo del mueble. Asimismo, se relevan las formas de represión estatal y paraestatal en un período clave de la historia nacional.
\end{abstract}

Palabras clave: conflictividad social, trabajadores, industria de la madera y el mueble, corrientes de izquierda, inmigración judía, represión, Ciudad de Buenos Aires.

\begin{abstract}
This article examines the social struggle in the city of Buenos Aires between 1909 and 1910, focusing on woodworkers and cabinet makers. Through the case study, the paper analyzes the forms of struggle and organization, the incidence of craftmanship in a barely mechanized field, the intervention of leftwing politics, and the role that ethnic relations played, in particular that of Jewish immigration in the furniture making industry. Moreover, the article researches the forms of state and parastatal repression in a key period of national history.
\end{abstract}

Keywords: Social struggle, workers, wood and furniture industry, left-wing politics, Jewish immigration, repression, Buenos Aires. 


\section{Introducción}

El presente artículo analiza el intenso período de alza huelguística y movilización popular que se desarrolló en la ciudad de Buenos Aires durante los meses previos a los festejos del Centenario de 1910. Es conocida, en este punto, la represión que tuvo lugar en aquella ocasión por parte del Estado y las clases dominantes. Menos estudiadas han sido, por el contrario, la dinámica de la conflictividad laboral y las formas de estructuración sindical y política que desplegó el movimiento obrero.

Para desarrollar la indagación, nos situaremos en la perspectiva de los trabajadores de la madera y el mueble de Buenos Aires, una de las industrias más destacadas de la época en razón de su importancia dentro del acelerado proceso de desarrollo urbano que transitaba la ciudad, y que ocupaba un lugar insustituible en aspectos nodales del hinterland porteño: la actividad de construcción, la producción de herramientas, el amueblamiento, la pavimentación de calles, el envasado de sustancias y alimentos e, incluso, el transporte terrestre y marítimo, entre los rubros más sobresalientes. ${ }^{1}$ Asimismo, la madera y la chapa de zinc predominaban en conventillos y casillas, y representaban el principal patrón del hábitat urbano popular.

La elección de analizar el mundo de la madera porteño permitió investigar un sector cuyo proceso productivo presentaba una morfología que semejaba, en la mayoría de los talleres, un conjunto de artesanos bajo un estadio de desarrollo de cooperación simple, con una escasa división del trabajo, antes que la configuración propia de la gran industria capitalista, con un alto grado de mecanización (Marx, 2008 [1867]: 451-470). No obstante, existían algunas pocas grandes fábricas de muebles, de carruajes y aserraderos que reunían a centenares de obreros divididos por secciones de oficio y equipados con poderosos motores, sierras y otras máquinas. La introducción de la maquinaria dentro del proceso de trabajo fue tardía en comparación con otras ramas (como las artes gráficas o la metalurgia) y, en general, el empresariado tendió a comportarse de forma dual, ora como fabricante, ora como importador (Rocchi, 1994: 49-55). El trabajo a domicilio, por otra parte, prevalecía en labores como la tapicería, la escultura o la marquetería. La mayoría de los talleres, conocidos por el nombre de «boliches», estaban geográficamente dispersos y ocupaban a un promedio entre cinco y diez obreros. ${ }^{2}$ En suma, el sector presentaba la peculiaridad de una triple configuración productiva entre los pequeños talleres, las fábricas y el trabajo a domicilio.

1. El mundo del trabajo maderero envolvía oficios de diversa calificación y variada posición en la economía urbana: carpinteros (en talleres pequeños y medianos, obras de construcción, el puerto), aserradores, constructores de carruajes y de carros, ebanistas, escultores, tapiceros, torneros, lustradores. Además, existía un abigarrado universo de peones sin cualificación y jóvenes aprendices (en general, de escasa edad), empleados en talleres y fábricas.

2. De acuerdo con los datos del censo industrial y comercial de 1908-1914 referidos a la Capital Federal, 4.159 carpinteros se empleaban en 882 talleres, lo cual arroja un promedio de 4,7 obreros por establecimiento, mientras que en las mueblerías este porcentaje era ligeramente más elevado: 3.107 trabajadores se repartían en 606 lugares (5,1 en promedio). Véase Censo (1915). 
El enfoque particular sobre el caso de la industria maderera permitió reducir la escala de análisis y profundizar la mirada sobre aspectos o dimensiones muchas veces desestimados. En este trabajo, por lo tanto, se propone reflexionar sobre el oficio y las relaciones étnicas desde la óptica de una industria mayormente artesanal, como fue la producción mueblera de Buenos Aires hasta mediados de la década de 1920, al igual que otras disciplinas conexas, como la escultura, la tornería o la tapicería (Everley, 1919: 4). En estos oficios, el trabajo cualificado (skilled work) resultaba el camino principal sobre el cual transcurría la organización, de donde derivaba un conjunto de peculiaridades que informaron las luchas, la estructuración sindical y la conciencia obrera (Montgomery, 1979: 10-12). De alguna manera, el oficio y el grado jerárquico de cualificación operaban como una línea divisoria entre los universos laborales.

En la ciudad de Buenos Aires del primer cuarto de siglo, los ebanistas - un sector clave del gremio maderero- presentaron una trayectoria semejante a otros obreros cualificados, en los cuales el skilled work aparecía rodeado por un aura de respetabilidad, conocimiento especializado y secretos artesanales transmitidos generacionalmente, conformando una cultura tradicional centrada en el trabajo y las reglas del oficio (Jones, 2014: 199). Fuera de los talleres, las fuentes de sociabilidad enmarcaban un ethos donde la endogamia, la tendencia hereditaria del aprendizaje y cierta forma distintiva de hablar y vestir constituían otros rasgos que reforzaban la solidaridad gremial. Desde la fundación del Sindicato de Ebanistas, Similares y Anexos, en 1896, estos trabajadores cimentaron una sólida estructuración sindical y ocuparon un lugar central en las primeras experiencias federativas del movimiento obrero argentino. Por esta suma de condiciones, desde finales del siglo XIX las corrientes de izquierda tuvieron una fecunda intervención en el sector, formulando distintos repertorios de organización y de lucha.

Aunque resulte lógico en una sociedad abrumadoramente cosmopolita como era Buenos Aires en la década del 1900, una peculiaridad de la industria del mueble porteña - en contraste con otros sectores productivos - fue el alto porcentaje de obreros de origen judío (llamados de forma indistinta «rusos»). ${ }^{3}$ A partir de 1905, la derrota de la Revolución rusa forzó el arribo de una corriente migratoria que huía de la represión y los pogroms, coincidiendo con el comienzo de la proliferación de los boliches, dedicados a la fabricación y venta de muebles baratos, donde se empleaban distintas formas de trabajo a destajo. Al pagarse jornales por pieza, los bolicheros rusos producían por un precio menor y agudizaban la competencia comercial. Si en 1904 el sector declaró transacciones por un valor de 4 millones de pesos, en 1907 esta cifra ascendió a 7 millones (Benario, 1940: 75). La competencia, por otra parte, oponía tanto a capitalistas como a trabajadores. Para los rusos, que anhelaban un

3. A la hora de cuantificar la unidad de análisis, el nudo de la cuestión reside en poder separar a los rusos de los judíos, tarea dificultosa debido, en parte, a que las fuentes (escritas en ídish) los referían como «israelita/s» 0 «ruso/s». Emplearemos el término «rusos» para nombrar a aquellos trabajadores judíos inmigrantes de la región de Europa del Este, en particular, de la «zona de residencia» (Mirelman, 1988: III). 
progreso económico y social, era natural trabajar a destajo, y contemplaban al sindicato como «una desgracia que quería robarles algunas horas de trabajo por día» (Brusilovsky, 1940: 5). Desde la perspectiva sindical, los boliches significaban «la ruina de la profesión» y una presión constante por nivelar hacia abajo las condiciones laborales (Bilsky, 1992: 44). Como veremos, el análisis sobre el sector judío atañe aspectos étnicos, aunque remite también a un mundo obrero atravesado por problemáticas laborales. En este plano, las izquierdas presentaron un conjunto de iniciativas y modulaciones tácticas que facilitaron o bloquearon, según el caso, la asimilación política y la estructuración sindical.

El objetivo general de este artículo es analizar la conflictividad social, las formas de organización y las relaciones étnicas y laborales de los trabajadores de la madera y el mueble de Ciudad de Buenos Aires entre 1909 y 1910, así como las formas que asumió la represión durante la Semana Roja de 1909 y el Centenario de 1910. La hipótesis que guio la pesquisa plantea que existieron intervenciones diferenciadas en los procesos huelguísticos según las modulaciones tácticas de cada gremio y corriente política, por lo que se ahondaron las diferencias entre cada sector obrero en función de diversas variables, tales como el nivel de cualificación, las formas del proceso productivo, las vías de estructuración sindical y cierta tradición gremial, entre otros factores relevantes.

De esta manera, se indagará sobre el aspecto menos conocido en la dialéctica entre capital y trabajo, enriqueciendo el abordaje relacional. En efecto, si bien el fenómeno represivo ha sido mayormente relevado por la historiografía - antes que el período temporal en sí-, un análisis tamizado por las dimensiones señaladas (mundo del trabajo, relaciones étnicas, culturas políticas) permitiría comprender otras aristas más complejas de la violencia estatal y paraestatal, como la articulación entre una y otra, sus efectos en los sitios laborales o su direccionamiento particular contra la población judía del barrio del Once y los militantes anarquistas. De igual modo, existieron otras mediaciones en la relación conflictividad-represión, ya sea por parte del novel Departamento Nacional del Trabajo (DNT), creado en 1907, ya sea desde el propio poder político.

En síntesis, el artículo desarrolla un análisis sincrónico entre 1909 y 1910, siguiendo las curvas de conflictividad y represión. En el primer apartado se aborda el mundo del trabajo ídish y las culturas políticas de izquierda intervinientes; en segundo lugar, se estudia el convulsivo año 1909 y su continuidad en las huelgas previas al Centenario; por último, se analiza la dinámica represiva de 1910, la reacción del movimiento obrero y su impacto específico sobre un sector de la población judía. Entre las fuentes utilizadas se destacan: periódicos de las corrientes políticas, prensa gremial, diarios de tirada masiva, boletines del Departamento Nacional del Trabajo (DNT) y un artículo inédito en español sobre el movimiento obrero judío, escrito por quien fuera ebanista y activista gremial (Brusilovsky, 1940). La diversidad de fuentes, en última instancia, expresa la necesidad por desentrañar la complejidad del objeto bajo estudio desde un prisma que contemple distintas dimensiones y miradas, las cuales atraviesan, de un modo u otro, los registros sobre los cuales se conformó esta investigación. 


\section{El mundo del trabajo ídish y las izquierdas}

A pesar de representar uno de los años más convulsivos de la historia argentina, 1909 ha recibido una escasa atención por parte de la historiografía (Frydenberg y Ruffo, 1992; Marotta, 1961; Belkin, 2019; Franco, 2019). Sin embargo, fue un año cruzado por importantes sucesos: la Semana Roja, en mayo; la formación de la Confederación Obrera de la República Argentina (CORA), en septiembre; la huelga general en repulsa del fusilamiento del anarquista y pedagogo catalán, Francisco Ferrer, en octubre; y, al mes siguiente, el asesinato del jefe policial Ramón Falcón a manos de un joven libertario de origen ruso, Simón Radowitzky. En el mundo de la madera, según el DNT, se desarrollaron 28 huelgas, sobre un total de 138 en la ciudad de Buenos Aires, que involucraron a 885 obreros (de los cuales 84 eran niños aprendices en talleres ebanistas). ${ }^{4}$ La irrupción de la conflictividad se dio con antelación al ciclo huelguístico general y provino de un sector inesperado: los obreros muebleros de origen judío.

La situación de estos trabajadores era contradictoria: si bien ejercían un oficio difícilmente sustituible por rompehuelgas, otros obstáculos, como el idioma y cierta tendencia al aislamiento, sumados, además, a la baja concentración de empleados por sitio laboral y a la cercanía étnica (y hasta social) con los patrones, se configuraban como una serie de factores que trababan su organización. Dentro de los boliches, las condiciones de trabajo eran pésimas, la organización sindical, inexistente, y las jornadas, superiores a las doce horas, por jornales ínfimos y, en general, pagados a destiempo. Asimismo, era común el empleo de menores, quienes soportaban la sobreexplotación y el maltrato. A diferencia de otros patrones del ramo, que solían ser exobreros que habían acumulado un capital y se habían establecido por su cuenta (en razón del escaso desarrollo productivo del sector), los bolicheros judíos solían desconocer el oficio (Brusilovsky, 1940: 4). En estos sitios minúsculos, sin ventilación ni iluminación adecuadas, las virutas cubrían el piso, el aserrín flotaba en el aire y apenas había higiene, por lo que el contagio de tuberculosis y otras enfermedades era frecuente.

La necesidad de organizar a los muebleros judíos había cobrado visibilidad en 1908, a partir de la huelga «de la chapa», cuando en un contexto de retracción de las luchas y de reflujo del movimiento obrero, los ebanistas rusos sostuvieron un paro de actividades durante semanas con el fin de abolir el trabajo a destajo, objetivo que consiguieron en un principio, aunque luego el acuerdo fue vulnerado. ${ }^{5}$

Con este antecedente, a finales de 1908 se reactivó el movimiento huelguístico en el ramo con el propósito de eliminar el destajo. Para organizar el reclamo, un núcleo de sindicalistas, junto con el militante ídish Israel Landan, desarrollaron una «campaña de reorganización» mediante reuniones con los ebanistas ru-

4. Boletín del Departamento Nacional del Trabajo, Buenos Aires, núm. 12, marzo de 1910, pág. 240.

5. El nombre del conflicto aludía al hecho de que una parte de la producción judía era de muebles enchapados baratos, al estilo «francés» (Brusilovsky, 1940: 4). 
sos y acordaron solicitar un aumento salarial. ${ }^{6}$ A comienzos de enero de 1909, el pliego fue rechazado por los bolicheros judíos y se declaró la huelga «del pino tea», que abarcó a aquellos talleres en los que se producían muebles baratos hechos con madera de pino, del estilo «inglés». Al cabo de un mes, los patrones debieron ceder ante las exigencias obreras: abolieron el trabajo a destajo y establecieron un jornal diario, así como también acordaron la jornada de ocho horas $y$, en lugar del pedido original del 10\%, aceptaron un $5 \%$ de aumento salarial. ${ }^{7}$

Más allá de las suspicacias, el gremio ebanista entendía el riesgo que implicaba la sobreexplotación de los obreros judíos, por lo que el acompañamiento a la medida fue absoluto. ${ }^{8}$ Al respecto, no fue menor la gravitación del «estereotipo positivo» en la idea de «seguir el ejemplo de los compañeros rusos», en un contexto de baja conflictividad (Moya, 2004: 40). La brevedad del conflicto y los vínculos solidarios con el resto de los trabajadores expresaron de algún modo esta realidad contradictoria.

El nuevo marco laboral tuvo una vigencia fugaz: «el trabajo por pieza en grandes cantidades [...] siguió manteniéndose y se continuó trabajando los domingos» (Brusilovsky, 1940: 6). En los meses posteriores, los talleristas se valieron del clima represivo creado por el estado de sitio para retrotraer las condiciones acordadas y reimplantar el destajo. ${ }^{9}$ Por el contrario, en el plano organizativo, se votó incorporar a dos rusos a la comisión administrativa (CA) del sindicato, habilitando la propaganda ídish en el órgano periódico. Según Brusilovsky (1940: 7), esta nueva modulación fue posible «gracias a la presión de algunos bundistas, que ya entonces querían crear un fahrein ídish de carpinteros», como existía entre los sastres, los sombrereros y los panaderos.

El estudio de caso de la industria mueblera porteña, por lo tanto, matiza y complejiza aquellas explicaciones centradas exclusivamente en una subjetividad obrera que se estructuraba prima facie alrededor de la dimensión étniconacional. En este sentido, suele ser señalado el rol que cumplieron las cadenas migratorias, las sociedades mutuales y la lengua, entre los principales elementos aglutinantes (Devoto, 2007). Otros autores, en una posición intermedia entre la etnia y la clase, apuntaron el rol que jugaron los aspectos educativos y culturales en la integración de las sucesivas generaciones (Visacovsky, 2015). Finalmente, un tercer espectro de obras abordaron la extranjería desde una dimensión relativa a la clase y su estructuración política y sindical (Camarero, 2007). En suma, el desafío consiste en indagar las identidades y prácticas resultantes de una determinación híbrida entre las vivencias del ser obrero y el carácter extranjero, en este caso, perteneciente a la comunidad judía.

6. «Huelga general de los obreros rusos que trabajan en el pino de tea», El Obrero en Madera, Buenos Aires, núm. 28, enero de 1909.

7. «Triunfo completo de la huelga de los compañeros rusos», El Obrero en Madera, Buenos Aires, núm. 29, febrero de 1909.

8. «Comité Federal. Ebanistas. Informe presentado a la asamblea del gremio celebrada el 15 de abril», El Obrero en Madera, Buenos Aires, núm. 31, 1/6/1909.

9. «Historia del Sindicato de Ebanistas», El Obrero Ebanista, Buenos Aires, núm. 94, julio de 1920. Firmada por Ángel Renoldi. 
El análisis sobre la industria del mueble indicó un predominio de los lazos y de la solidaridad de clase por encima de la construcción social judío-ruso, al menos bajo una forma corporativa o sectorial, derivada de las características del oficio mueblero y sus disciplinas conexas (Koppmann, 2020: 169-170). Las necesidades de un movimiento gremial de obreros cualificados, como eran los ebanistas, que contaban con un alto nivel organizativo y deliberativo, ofrecían las condiciones de posibilidad para quebrar cierto hermetismo de la comunidad de origen e integrar a estos nuevos trabajadores dentro de las estructuras sindicales, bajo los usos, costumbres y reglamentaciones vigentes. De esta manera, se conjugó un terreno fértil para el desarrollo de un abigarrado universo de culturas políticas de izquierda.

Hacia 1908, las tres principales corrientes existentes en el seno del movimiento obrero judío eran los anarquistas (bajo distintas vertientes), los bundistas y los poalei-sionistas. Para apuntalar la intervención gremial, las distintas tendencias conformaron el Idisher Arbeiter Tzentr fur Profesionele Aguitatzion o Centro Obrero Judío para la Agitación Sindical (Bilsky, 1992: 46). En este contexto, diferentes publicaciones vieron la luz y tuvieron una existencia efímera, con la notable excepción del órgano periódico del Bund, Der Avangard (La Vanguardia). El perfil societal de estos primeros propagandistas era netamente obrero: «Ninguno de los dirigentes de los partidos judíos y los grupos anarquistas y ninguno de los escritores de estas publicaciones tenía formación académica. Todos eran trabajadores" (Brusilovsky, 1940: 7). Por estos años, La Vanguardia, La Protesta y otras publicaciones gremiales (como el periódico El Obrero en Madera), incorporaron una sección en ídish de forma más o menos intermitente. Dentro del diario libertario, por ejemplo, los poalei-sionistas escribían la sección judía («ldishe Abtheilung»), a pesar de ser opositores al anarquismo (Díaz, 2016: 134). En este período, el mundo ácrata dentro del universo judío estaba compuesto por una amalgama de tendencias: las posturas individualistas, cercanas a Proudhon y Stirner; aquellas de carácter colectivista, influidas por Bakunin; las situadas en el espectro comunista de Kropotkin; y el anarcosindicalismo, representado por el español Lorenzo (Suriano, 2001: 185-210). En cualquier caso, resulta ineludible la gravitación de la cultura política anarquista entre los obreros rusos que arribaron a Buenos Aires durante la primera década del siglo XX, plasmada en agrupaciones, locales, periódicos y bibliotecas, entre otras tantas iniciativas.

En una mirada panorámica, se podrían identificar - al menos - tres factores que explicarían la destacada presencia libertaria. En primer lugar, a diferencia de los socialistas - que requerían la nacionalización del obrero para desenvolver su política en clave parlamentaria-electoral-, los anarquistas no se oponían a una organización según origen étnico o lengua (aunque no así dentro de los gremios), situación que se vio facilitada, además, por la naturaleza descentralizada de la actividad anarquista. Un segundo factor fue el universo de sentidos y prácticas tejido alrededor de la educación, considerada como una vía de progreso y liberación, rasgo este compartido por socialistas y anarquistas. Por último, deben considerarse las trayectorias militantes de muchos trabajadores inmigrantes, acumuladas durante décadas en la Rusia natal, donde el movimiento ácrata era uno de los más prolíficos del mundo. 
La segunda cultura política destacable eran los militantes del Bund (socialistas que rechazaban la postura "asimilacionista", explicada abajo), los cuales contaban con un grupo afín dentro del sindicato del mueble (Bilsky, 1992: 4548). Los bundistas reivindicaban la independencia de clase frente a la hegemonía de la élite judía sobre los trabajadores y planteaban la necesidad de una autonomía nacional. Entre 1908 y 1910 y luego con posterioridad a 1916, editaron el periódico Der Avangard, que reflejaba «la opinión de lo social-judío antes que las problemáticas de los trabajadores". Así, quienes querían trabajar más horas o por un salario menor "encontraban en el partido la mikve ${ }^{10}$ donde sumergirse y curarse de todos sus pecados» (Brusilovsky, 1940: 8).

Un tercer conjunto eran los grupos sionistas socialistas, cuyo primer núcleo data de 1906; estos publicaron los periódicos Dos Ídishe Lebn (La Vida Judía) y Najrijten (Noticias). Al año siguiente, cristalizó un núcleo poalei-sionista, gracias a que la agrupación sumó a los socialistas borojovistas (seguidores de Borojov, teórico del sionismo socialista) (Bilsky, 1992: 46). No obstante, estos grupos se desactivaron al poco tiempo, pero volvieron a intervenir circa 1917. Si bien con menor presencia que los bundistas, los poalei-sionistas desempeñaron roles dirigentes en algunos sindicatos, como Vexman, entre los sastres, o Krim y Solmetski, en el mueble (Brusilovsky, 1940: 9).

Párrafo aparte merece el Partido Socialista (PS) argentino, cuya peculiar configuración bajo el mando de Juan B. Justo buscó asimilar los conjuntos étnicos mediante su naturalización. El propósito subyacente era constituir una fuerza política que modernizara el Estado y la sociedad. En el ambiente judío, los iskristas (partidarios del periódico Iskra - La Chispa-, publicado por la fracción de Lenin) sostuvieron la necesidad de asimilarse a las estructuras formales del PS y de nacionalizarse.

Al finalizar el recorrido sobre las corrientes de izquierda en el mundo obrero judío, se destacan las dificultades de asimilación/integración por parte de estos trabajadores, tanto en el terreno de los agrupamientos políticos como dentro de los fahreins. En efecto, no pocos obreros socialistas o anarquistas se consideraban a sí mismos por encima del sindicato, pues entendían que allí se desarrollaba una pelea por migajas. Por otro lado, la propaganda ídish colaboraba, aunque de forma muy limitada ya que los "oradores y escritores judíos de los partidos volaban, como se expresó Zhitlowsky, ${ }^{11}$ en los zafiros de la abstracción celeste» (Brusilovsky, 1940: 10). En este cuadro, la incorporación de los rusos a los sindicatos fue dificultosa y demandó años de experiencia.

10. Bañera para el baño ritual.

11. El articulista se refería al filósofo y escritor judío yidishista, Chaim Zhitlowsky, fundador del Partido Socialista Revolucionario ruso. 


\section{La Semana Roja y sus derivas}

La Semana Roja fue uno de los episodios más destacados y quizá menos atendidos en la historia de los trabajadores de Argentina. Los hechos, de cualquier modo, son conocidos: en la movilización anarquista del 1 de mayo de 1909, una de las columnas de la Federación Obrera Regional Argentina (FORA) fue atacada por las tropas de policía cuando atravesaba la plaza Lorea, con un saldo de diez muertos (entre ellos un joven judío de 22 años, Jacobo Resnicoff) y centenares de heridos (Dickmann, 1949: 158). Como si el ataque hubiera sido premeditado, los bomberos rápidamente limpiaron la sangre de las calles y los carros del servicio sanitario desaparecieron los cadáveres. En pocas horas, no obstante, los sucesos llegaron a oídos de todos, incluida la manifestación socialista que se dirigía a plaza Colón; a través de la figura de Alfredo Palacios, una multitud vitoreó la huelga general y exigió la renuncia del jefe de la policía, Ramón Falcón. Por la noche, se reunieron las direcciones de la Unión General de Trabajadores (UGT) y la FORA con el objetivo de convocar a la acción, e idéntica actitud adoptó el comité ejecutivo del PS. ${ }^{12}$

Aunque parecía primar la unidad, un análisis más minucioso permite entrever una clara línea divisoria entre las tres corrientes intervinientes: mientras que los socialistas reclamaban la renuncia de Falcón, para los sindicalistas y los anarquistas esta no era prioritaria e, incluso más, de concretarse, funcionaría como una suerte de relevo para la desgastada figura del jefe policial..$^{13}$ La libertad de los presos y la derogación de la legislación municipal sobre los choferes, por ende, fueron las reivindicaciones que levantaron la UGT, la FORA y los gremios «autónomos». ${ }^{14}$

A partir del lunes 3, la ciudad de Buenos Aires amaneció paralizada, «tranquila y silenciosa»; solo unos pocos lugares de trabajo y pequeños comercios abrieron sus puertas. ${ }^{15}$ El despliegue de la huelga, que arrastró a unos doscientos mil o trescientos mil trabajadores, fortaleció la capacidad de movilización de las masas frente a la masacre del Estado. Así, alrededor de ochenta mil manifestantes (según los organizadores) acompañaron el cortejo fúnebre con los restos de los asesinados en la jornada del 1 de mayo. Al finalizar, tuvo lugar el único acto conjunto entre sindicalistas, socialistas, anarquistas y gremios no agrupados en ninguna central; el resto de los mítines públicos fueron realizados de forma separada.

12. «Elocuente despertar del proletariado: la huelga general, triunfo completo de la causa obrera», La Acción Socialista, Buenos Aires, núm. 89, 16/5/1909.

13. «Sindicalista» era la denominación más común en la época para los militantes de la corriente sindicalista revolucionaria; se utilizará la palabra en itálica cuando se refiera a esta tendencia.

14. La Unión de Chauffers tenía convocada una huelga para el lunes 3 de mayo en protesta contra una reglamentación municipal que exigía portar una libreta «de buena conducta». Es importante resaltar que los gremios autónomos superaban en número al total de sectores afiliados a las dos centrales (Marotta, 1961: 43).

15. «Ecos del $1^{\circ}$ de mayo», La Prensa, Buenos Aires, 3/5/1909. 
Durante el transcurso de la Semana Roja de mayo de 1909, las masas ganaron las calles de Buenos Aires. ${ }^{16}$ Aunque las reuniones y actos estaban prohibidos y la ciudad se encontraba militarizada por unos cinco mil soldados del ejército, la efervescencia social parecía incontenible:

[...] lejos de intimidarse el pueblo obrero, se indignó mayormente y las reuniones prohibidas en sus locales fueron realizadas en las plazas, en los lugares céntricos, en los barrios de la burguesía. La agitación reinaba en todas partes. Las calles ofrecían el aspecto de un desfile sin término de peatones. Las esquinas, las puertas de los conventillos y de los talleres, eran reuniones de huelguistas [...]. La revuelta en las fábricas y talleres se tradujo en una revuelta en la calle, manifestada por tumultos, pedradas y tiros. ${ }^{17}$

Piquetes y barricadas, combates callejeros, ataques contra los tranvías y trenes en funcionamiento, enfrentamientos con rompehuelgas, entre otras acciones, formaron parte del repertorio de organización popular, el cual persistió como una marca indeleble a través de décadas. ${ }^{18}$ Los diarios destacaron la participación de "grupos rusos", de los cuales «han partido los primeros disparos hechos contra la policía», portando además «manifiestos escritos en lengua hebrea, que encierran una propaganda violentísima». ${ }^{19}$ Desde el lado patronal-estatal, los esfuerzos por reemplazar a los huelguistas, mediante esquiroles o soldados, fueron inocuos. Entre las empresas que trataron de funcionar pese a la huelga, se encontraba la importante empresa de Juan y José Drysdale, cuyos talleres mecánicos y de aserrado se ubicaban en la vuelta de Rocha de La Boca. En estrecha colaboración con la Unión Protectora del Trabajo Libre (antecesora de la más conocida Asociación Nacional del Trabajo), la compañía, que también se dedicaba a las importaciones, prestó a la municipalidad porteña tres automóviles. ${ }^{20}$

El paro se prolongó durante siete días, al cabo de los cuales una comitiva obrera compuesta por la FORA, la UGT y los autónomos se entrevistó con el presidente previsional del Senado, Benito Villanueva, quien aceptó el conjunto de las demandas. Por la noche, se definieron los términos bajo los que se levantaría la huelga, y se amenazó con retomar la medida en caso de que los presos no fueran liberados. ${ }^{21} \mathrm{Al}$ concluir la Semana Roja, la vuelta a los sitios laborales estuvo marcada, en muchos casos, por una revancha patronal, pues hubo sanciones y despidos a participantes en el movimiento. En los talleres estatales del Riachuelo, centenas de carpinteros y aserradores fueron suspendidos por tres meses. ${ }^{22} \mathrm{Y}$ situaciones similares se repitieron en carpinterías, obras de cons-

16. "L'état de siège à Buenos Aires», La Vie Ouvrière, París, núm. 7, 5/1/1910. Firmada por James Guillaume.

17. «La grandiosa huelga general - El triunfo», El Obrero en Madera, Buenos Aires, núm. 31, $1 / 6 / 1909$

18. «La huelga general», La Razón, Buenos Aires, 4/5/1909.

19. «Ecos del $1^{\circ}$ de mayo», La Prensa, Buenos Aires, 3/5/1909.

20. «Repercusiones de la huelga», La Nación, Buenos Aires, núm. 12732, 7/5/1909.

21. «Reunión de delegados gremiales», La Vanguardia, Buenos Aires, núm. 1080, 9/5/1909.

22. «Huelgas. En los talleres del Riachuelo», La Vanguardia, Buenos Aires, núm. 1081, 11/5/1909. 
trucción y aserraderos, así como, fuera del mundo de la madera, en el sector ferroviario y tranviario. ${ }^{23}$

En el campo del movimiento sindical, las jornadas de mayo apuntalaron la corriente de opinión favorable a una unidad de las fuerzas obreras, superando la fragmentación político-ideológica. Así, los sindicalistas aprovecharon el impacto de la huelga general para reemprender los preparativos en pos de converger con las fuerzas ácratas y los gremios autónomos dentro de una estructura sindical común. ${ }^{24} \mathrm{El}$ «congreso de fusión» tuvo lugar el 25 y 26 de septiembre de 1909, y dejó conformada la CORA. ${ }^{25}$ Menos de un mes después, la situación política precipitó una vez más la confrontación de clases, poniendo a prueba a la flamante central. En el mundo de la madera, la réplica no fue menor.

A finales de julio de 1909, el Gobierno de España debía enviar un nuevo contingente de tropas para reforzar la ocupación imperialista de Marruecos. Sin embargo, un sector de los reservistas de Cataluña se negó, apoyado por franjas populares descontentas con el Estado y el clero, y así comenzó en Barcelona una huelga general que se extendió hacia otras localidades hasta adquirir un carácter insurreccional. ${ }^{26}$ En este cuadro, durante los días subsiguientes se incendiaron distintos edificios eclesiásticos y la ciudad se vio inmersa en una lluvia de cañonazos, que preparó la intervención militar. Como corolario de la Semana Trágica, una docena de militantes libertarios, entre los cuales se encontraba el pedagogo racionalista Francisco Ferrer, fueron detenidos en la prisión de Montjuïc y sentenciados a muerte. El repudio pronto se generalizó entre las organizaciones obreras del planeta, evidenciando el sentimiento internacionalista que envolvía a la clase trabajadora. En Argentina, la masacre de Barcelona concitó una masiva huelga general el 15 de octubre, capitaneada por la CORA, y realizó varios actos multitudinarios, algunos en conjunto con los anarquistas, en los que se convocaba a boicotear los productos españoles (Belkin, 2019: 118).

Volviendo a Buenos Aires, un mes después de la huelga por Ferrer, el choque entre las clases escaló en intensidad: un militante anarquista ruso, Simón Radowitzky, arrojó una bomba dentro del carruaje donde viajaban el jefe policial, Ramón Falcón, junto con su secretario, y acabó con la vida de ambos. Radowitzky, que contaba con 18 años, fue de inmediato detenido y sentenciado por la justicia y la opinión pública. ${ }^{27}$ Pocas horas después, el Poder Ejecutivo

23. «Asuntos gremiales. Represalias burguesas», La Protesta, Buenos Aires, núm. 1641, 11/5/1909; «Aserradores y anexos», La Vanguardia, Buenos Aires, núm. 1081, 11/5/1909; «Ecos de la gran huelga», La Protesta, Buenos Aires, núm. 1641, 11/5/1909.

24. «La fusión obrera», El Obrero en Madera, Buenos Aires, núm. 33, 1/8/1909.

25. «Confederación Obrera Regional Argentina», La Acción Sindicalista, Buenos Aires, núm. 103, $13 / 11 / 1909$.

26. «Huelga general en España», El Obrero en Madera, Buenos Aires, núm. 33, 1/8/1909.

27. Según el fiscal de la causa, Manuel Beltrán: «Simón Radovitzky pertenece a esta clase de ilotas que vegetan en las estepas rusas arrastrando su vida miserable entre las inclemencias de la naturaleza y las asperezas de una condición inferior [...]. En las consideraciones de la defensa social debemos ver en Radovitzky un elemento inadaptable cuya temibilidad está en razón directa con el delito perpetrado» (Lewin, 1983: 171-172). 
decretó el estado de sitio por sesenta días. En la madrugada, hordas policíacas y civiles se lanzaron sobre la imprenta de La Protesta y otros locales políticos y gremiales y los destruyeron de forma barbárica (Marotta, 1961: 40). ${ }^{28}$

Más allá de estos hechos, en general conocidos, nos interesa destacar la inmensa ola xenófoba que se generó en reacción, como si el odio de clase acumulado durante años hubiera encontrado por fin una justificación y un responsable de carne y hueso. Desde este momento, Simón Radowitzky se convirtió en la figura del heroísmo anarquista de la primera década del siglo e, inversamente, en el chivo expiatorio de los sectores reaccionarios. El vengador Radowitzky concentraba las cualidades para una u otra representación: joven, anarquista, ruso (más aún, judío), de rasgos acentuados (en una época de florecimiento de la doctrina criminal lombrosiana) y, fundamentalmente, instrumentador de una acción violenta, altruista y certera, que acabó con la vida de quien fuera responsable de la masacre contra la columna de la FORA el 1 de mayo de 1909. Para los anarquistas, la figura de Simón sería canonizada como el «salvador' y el ejemplo; para la burguesía argentina, como el elemento social perturbador par excellence. En esta dirección, la influencia de las izquierdas dentro de la comunidad judía reavivó de forma crónica el miedo de clase, acicateado por las revoluciones rusas de 1905 y 1917, el asesinato de Falcón (1909), la bomba en el teatro Colón (1910) y, de modo general, la efervescencia de la conflictividad obrera en los sectores donde abundaba la presencia del grupo étnico en cuestión. Además, un factor no menor que contribuía a reforzar este ideario era la dedicación de algunos judíos a la trata de mujeres, en particular, polacas.

En el mundo de la madera, estos acontecimientos replicaron con fuerza. Dentro de los talleres de la compañía inglesa Thompson, 150 ebanistas se sumaron al paro por Ferrer, y solo un obrero discrepó. Ante esta situación, solicitaron al dueño su despido y, al no obtener respuesta, decidieron paralizar las actividades. ${ }^{29}$ La huelga se prolongó por varios meses, logrando mantenerse incluso bajo el estado de sitio y concitando la solidaridad de los 40 tapiceros del taller. En este plano, se destaca, por un lado, el carácter insustituible del oficio especializado - que fortalecía la posición obrera pese al contexto hostil-y, por el otro, cierto componente de dignidad derivado de la labor artesanal, donde la sola negativa de un trabajador comprometió al conjunto. Como señalamos al comienzo, no se trataba de un colectivo obrero convencional. Al respecto, interesa notar que, en el marco del estado de sitio, se verificaron dos asambleas, que fueron autorizadas por la policía. ${ }^{30}$ En el desenlace, luego de 117 días de huelga, la patronal Thompson se avino a negociar, y abonó además una multa de 3.000 pesos en concepto de jornales perdidos.

28. «La mazorca», El Obrero en Madera, Buenos Aires, núm. 37, diciembre de 1909.

29. «Ebanistas y tapiceros», El Obrero en Madera, Buenos Aires, núm. 36, noviembre de 1909.

30. «Terminación de la huelga de ebanistas en los talleres de Thompson», El Obrero en Madera, Buenos Aires, núm. 38, febrero de 1910. 


\section{Las huelgas de la madera en los meses previos al Centenario}

Los meses previos al Centenario de 1910 alimentaron las discusiones entre la clase dominante sobre cuál debía ser la imagen que la Argentina presentara al mundo. Para ello, era necesario embellecer Buenos Aires, idealizada como la París de Sudamérica, según se repetía una y otra vez. Quizá una de las representaciones más convencionales de la belle époque sea aquella surcada por flamantes edificios públicos y con petits palaces levantándose en las principales arterias de la ciudad. Como podrá imaginarse, este escenario correspondía a la mirada de una minoría social, mientras que el panorama circundante era radicalmente diferente.

A la precariedad y miseria de las condiciones de trabajo y hábitat popular, se sumaba la tendencia alcista de los alquileres, que en 1907 había desatado la huelga de inquilinos. En los sitios laborales, el año 1910 presenció la importante cifra de 298 huelgas en la ciudad de Buenos Aires (contra 148 en 1909 y 118 en 1908), con la sugestiva ausencia de conflictos en los dos últimos trimestres, como producto elocuente de la envergadura de la represión del Centenario. ${ }^{31}$ Sobre este total, 126 fueron protagonizados por trabajadores del sector bajo estudio. 32

En el mundo de la madera, una huelga de aserradores paralizó a finales de enero los talleres de la Boca y Barracas durante más de un mes, con la reclamación de un seguro sobre accidentes, así como de la jornada de ocho horas; con ello, logró un acuerdo. ${ }^{33} \mathrm{El}$ momento no era azaroso ya que el sector tendía a movilizarse en sincronía con la conflictividad del puerto, ligada a los ciclos de la cosecha y la logística comercial. En esta dirección, unos dos mil marineros y foguistas también declararon un paro de actividades por esta fecha. ${ }^{34}$ Durante los meses sucesivos, ebanistas, carpinteros, torneros, escultores, galponistas y constructores de carruajes, entre muchos otros sectores, se lanzaron a reclamar mejores condiciones laborales.

Entre los ebanistas y carpinteros, salvando las distancias entre ambos universos gremiales, el principal motivo de agitación era conquistar la abolición del banco y las herramientas, aunque también el abono de los viáticos a quienes trabajasen fuera del taller. ${ }^{35}$ Además del gasto que implicaba para los obreros, la provisión de materiales por parte de los talleristas constituía una barrera limitante a la multiplicación de boliches. Asimismo, desde la óptica sindicalista, no era ajeno el horizonte estratégico hacia el dominio obrero de la producción social. ${ }^{36}$ Los torneros también se sumaron al movimiento mueblero, reorganizando

31. Boletín del Departamento Nacional del Trabajo, Buenos Aires, núm. 16, marzo de 1911, pág. 219.

32. Ibídem, págs. 220-221.

33. «Movimiento obrero. Declaración de la huelga de los Aserradores y anexos», La Protesta, Buenos Aires, núm. 1808, 28/1/1910.

34. «Agitación gremial. Foguistas marítimos», La Vanguardia, Buenos Aires, núm. 1238, 1/2/1910.

35. «Movimiento obrero. Las huelgas. Carpinteros y anexos", La Protesta, Buenos Aires, núm. $1826,2 / 3 / 1910$.

36. «El banco y las herramientas», El Obrero en Madera, Buenos Aires, núm. 32, julio de 1909. 
la sociedad luego de tres años de inactividad. Entre los reclamos, figuraba uno muy arraigado en la constitución artesanal del gremio, relativo al aprendizaje: «Ningún taller podrá tener más de cuatro ayudantes por oficial». ${ }^{37}$ Durante las décadas subsiguientes, y frente a la introducción paulatina de la manufactura en el proceso productivo, las disputas entre obreros y patrones sobre las condiciones del aprendizaje fueron un foco permanente de conflicto.

Entre los constructores de carruajes, a pesar de su sólida trayectoria organizativa, ciertas mutaciones del proceso de trabajo posibilitaron que se generalizara la descentralización productiva hacia cocherías, boliches y domicilios particulares, volviendo endeble la estructuración sindical. Según se denunciaba, "se pintan y tapizan los carruajes de un modo propiamente lamentable, se estropea el oficio y se contribuye a mantener un contingente permanente de compañeros desocupados». ${ }^{38}$ Desde el sindicato, se convocaba a luchar por la centralización de las labores «porque en las fábricas por mal que se haga el trabajo, siempre mejor que en las cocherías se hace y por eso se emplea más tiempo lo que da lugar a que en vez que lo haga todo un obrero solo, lo hagan dos». ${ }^{39}$ En buena medida, se trataba de una lucha que envolvía la dignidad yel orgullo de oficio contra cierta tendencia a la descalificación y la sobreexplotación.

\section{Represión, xenofobia y antisemitismo}

En las vísperas del Centenario, los oficios madereros más numerosos, como los carpinteros y los ebanistas, se encontraban en huelga, mientras que otros subsectores habían desarrollado movimientos generales, con mayor o menor éxito. A su vez, el hecho de conquistar mejores condiciones y derechos laborales exigía sostener cierto grado de estructuración sindical en los talleres, lo cual respaldaba los acuerdos con los capitalistas dentro de una relación de fuerzas cambiante. Al impulso de la conflictividad laboral se coligó la iniciativa de anarquistas y sindicalistas para convertir los festejos de mayo en una gran protesta cuyo reclamo central fue la derogación de la «ley de residencia», sancionada por Julio Roca en $1902 .{ }^{40}$ Por otra parte, muchos detenidos durante la Semana Roja de 1909 seguían en la cárcel.

A finales de marzo, la CORA convocó una reunión de delegados «para acordar y determinar la declaración de huelga general»..41 Luego de varios encuentros, la mitad de los presentes (dieciséis delegados) se pronunció a favor mientras que el resto votó en contra o se abstuvo. En el campo de los libertarios, las

37. «Torneros en madera», El Obrero en Madera, Buenos Aires, núm. 40 y 41, 1/5/1910.

38. «A todos», El Obrero Constructor de Rodados, Buenos Aires, núm. 30, marzo de 1909. Firmado por Bartolomé Ruffinengo.

39. Ídem.

40. «Lo que debemos hacer», El Obrero Constructor de Rodados, Buenos Aires, núm. 40, enero de 1910.

41. «Confederación Obrera Regional Argentina», La Acción Socialista, Buenos Aires, núm. 117, 26/3/1910. 
dudas parecían dominar los pronósticos, al menos en lo que respecta a la actitud asumida por la dirección de la FORA, que ignoró el llamamiento a la huelga general de la otra central y, en cambio, apeló a la vía institucional, reuniéndose el 7 de mayo con el ministro de interior, José Gálvez, para solicitar la revocación de la ley de residencia, la libertad de los presos políticos y la amnistía a los infractores del servicio militar obligatorio, sin conseguirlo. ${ }^{42}$

Al día siguiente, una multitud popular ganó las calles de Buenos Aires en una de las movilizaciones más numerosas que hubiera conocido la ciudad hasta ese momento. Organizada por el "comité de agitación contra la ley de residencia», formado desde la misma FORA, se leyó una declaración en la que se afirmaba que, de no concederse los reclamos antes del 18 de mayo, «el pueblo» iría a la huelga general (Belkin, 2019: 132). En los días sucesivos, los hechos se precipitaron y la situación se deterioró con rapidez. Luego de fustigar a los anarquistas por su falta de resolución, el 12 de mayo la CORA sindicalista fijó el inicio de la huelga para el 18 de mayo. ${ }^{43}$ Para el Gobierno, la evidencia era suficiente. En pocas horas, decenas de militantes y dirigentes obreros fueron encarcelados, se asaltaron las redacciones de La Protesta y La Batalla y se allanaron los domicilios particulares. Las fuentes denunciaban entre cien y trescientos detenidos, aunque, según Marotta (1961: 77), fueron más de quinientos; además: «El tratamiento jamás había sido tan inhumano, y eso que en el pasado no se escatimó violencia. El preso obrero constituía una bestia; como tal se le trataba» (Marotta, 1961: 77). Aunque ya regía de hecho, el 14 de mayo una sesión parlamentaria extraordinaria decretó el estado de sitio, lo cual fue la señal que esperaban las bandas paramilitares para sumarse a la represión estatal.

El grado de ferocidad y violencia de los ataques de mayo de 1910 contra la clase obrera no representa, sin embargo, un elemento original ni mucho menos inédito en la historia nacional; no obstante, deben subrayarse la intensidad que asumió la represión y su alcance posterior (Iñigo Carrera, 2013: 85-96). Unas horas antes, la prensa había recibido instrucciones por las que se prohibía hacer mención a los hechos, así como informar sobre los detenidos o publicar textos contestatarios.

Los episodios del 14 de mayo son conocidos: una turbamulta iracunda, encabezada por miembros de la oligarquía, un sector de los altos mandos del aparato represivo y una columna de estudiantes de secundaria y universitarios partieron del Jockey Club y se dirigieron, en primer lugar, al local que alojaba la imprenta de La Protesta, para destrozarlo a los gritos de «iViva la patria! ¡Muerte al anarquismo! ¡Abajo la huelga! ¡Mueran los obreros!»; fueron luego a su homónimo socialista, y repitieron el mismo modus operandi vandálico. Es tristemente célebre la escena del reproche de Juan B. Justo - líder del PS argentino y, poco tiempo después, diputado electo- al comisario Reynoso, en pleno ataque contra el local, y la respuesta de este: «iQué quiere, doctor, los muchachos están

42. «Petición de la Federación Obrera: entrevista de delegados con el ministro del interior», La Nación, Buenos Aires, núm. 12733, 8/5/1910.

43. «La comisión de la FORA», La Acción Socialista, Buenos Aires, núm. 124, 14/5/1910. 
entusiasmados!»..$^{44}$ Consumados estos actos, los grupos de choque se dirigieron al local colectivo de México 2070, donde se alojaban, entre otros, los sindicatos de ebanistas y de escultores en madera y la redacción de La Acción Socialista. Luego de que obreros armados repelieran el primer ataque desde el tejado, las hordas volvieron en compañía de más policías y bomberos, destruyeron los locales sindicales $y$, en un acto de gran simbolismo, izaron la bandera argentina, mientras otros, presos de gran exaltación, encendían hogueras con los materiales y muebles que habían destruido. ${ }^{45}$ La siguiente parada fue el barrio proletario de La Boca; sin embargo, varios concurrentes advirtieron que los trabajadores, enterados de la ferocidad de los atentados, habían levantado barricadas y los estaban esperando.

La violencia organizada desde sectores civiles no era un elemento novedoso en la vida política nacional. Por estos años, la oligarquía se había hecho famosa por su inclinación a la denominada mala vida, cuyo prototipo hacía grandes escándalos, pegaba bastonazos y disparaba su revólver para imponer su voluntad. Esta clase de violencia social se extendía y reproducía dentro de ámbitos recreativos, como el prostíbulo, el cabaret o el club social, donde los muchachos acomodados y buena parte de los hombres adultos solían pasar su tiempo.

En comparación con la represión sobre el movimiento obrero, menos conocido fue el pogrom ocurrido durante las noches del 14, 15 y 16 de mayo, cuando encabezadas por el general Luis Dellepiane «las patotas policiales y burguesas, en busca de "terroristas" se lanzaron sobre el barrio ruso, situado en la calle Lavalle de Callao a Ombú [actual Pasteur]", es decir, el barrio de Once y sus alrededores. ${ }^{46}$ Se trata del primer ataque colectivo contra judíos en la historia argentina del cual se tenga registro, casi una década antes de la más afamada masacre en el curso de la Semana Trágica de enero de 1919; con frecuencia, el pogrom de 1910 en Buenos Aires ha sido ignorado. Como en otros casos, las dimensiones de la masacre son difíciles de establecer. No obstante, las fuentes relatan cruentas torturas, varios heridos y apaleados, profusas violaciones contra las mujeres y actos incendiarios contra negocios y viviendas; entre otros lugares emblemáticos, fue asaltado el local del centro socialista Avangard, donde funcionaba la «biblioteca rusa», compuesta por más de 2.500 volúmenes en ídish, que fueron quemados en la calle y secuestrados en su totalidad. ${ }^{47}$

Las raíces sociales de la persecución contra los judíos, por otra parte, encierran una trama compleja. La Argentina no había permanecido inmune a la corriente global que divulgaba el mito de un complot judío para dominar las naciones (Lvovich, 2003: 46), de lo cual se derivaban estereotipos muchas veces

44. «Bajo el imperio de la barbarie burguesa. La canalla burguesa-policial, asalta e incendia los locales obreros", La Acción Socialista, Buenos Aires, núm. 125, 14/6/1910.

45. «Notas y comentarios», La Acción Socialista, Buenos Aires, núm. 126, 29/6/1910.

46. «En el Centenario de la Revolución por la Libertad. Los atentados contra el pueblo trabajador», La Vanguardia, Buenos Aires, núm. 1386, 30/9/1910.

47. Ídem. 
contradictorios entre sí, como los de trabajadores subversivos (enrolados en corrientes de izquierda) y patrones explotadores. La xenofobia y el antisemitismo convergieron en un «nacionalismo cultural» que, a finales de la primera década del siglo $x x$, pivotaba sobre un rechazo al positivismo y al cosmopolitismo. La xenofobia, por ende, funcionaba como un argumento más en defensa del orden frente a la era de la política de masas.

En el balance de las jornadas de mayo de 1910, debe señalarse el lugar de la resistencia obrera frente a la violencia represiva. Con la declaración del estado de sitio el 13 de mayo, la clase trabajadora inició un paro de actividades que, a pesar de los ataques, se hizo sentir con fuerza en el puerto, entre los conductores de carros, los panaderos, los obreros de la construcción y de las distintas industrias e, incluso, entre muchos de los trabajadores de las exposiciones del Centenario (Marotta, 1961: 78). En los barrios, se dieron formas de autodefensa obrera y combates callejeros. Bajo la represión, también continuó la huelga ebanista, que para este momento llevaba varias semanas y que, a pesar de contar con la firma de más de doscientos talleristas, enfrentó con éxito un lockout organizado por exmilitantes del sindicato devenidos en dueños, y logró al final la obtención de las herramientas grandes. ${ }^{48}$ Entre los presos políticos figuraban los principales militantes de todas las corrientes, entre otros: los sindicalistas Cuomo, Malfatto, Montale, Marinelli y Lotito; los anarquistas Gilimón, Balzán (ambos luego deportados), Rodríguez Pacheco, Antilli y Barrera; y el cuadro judío del mueble, Landan, y sus dos hermanos.

Un mes después de los festejos centenarios, el 26 de junio una bomba explotó en el teatro Colón y causó una conmoción de carácter social antes que material, que acabó con el procesamiento del anarquista ruso Romanoff. Al día siguiente y como corolario de la ofensiva represora, el Parlamento aprobó una ley de «defensa social», que impedía el ingreso al país a cualquier sospechoso de atentar «contra el orden social» y prohibía cualquier asociación o reunión «que tuviesen por objeto la propaganda del anarquismo o la preparación e instigación de hechos reprimidos por las leyes» (Marotta, 1961: 81-84). Con estas medidas disciplinares, se cerraba uno de los capítulos más oscuros de la historia nacional.

\section{Conclusiones}

En este artículo hemos desarrollado un análisis focalizado en el punto más alto de la lucha de clases de la primera década del siglo xx. A partir del estudio de caso de la industria maderera, se indagaron las formas de conflictividad y organización, el rol del oficio en el gremio, las peculiaridades del sector judío del mueble y las modulaciones que asumió la violencia estatal y paraestatal.

48. «Ebanistas», La Acción Socialista, Buenos Aires, núm. 125, 14/6/1910. 
La profundidad de la represión de 1910 sobre el movimiento obrero fue tal que sus efectos perduraron durante meses e incluso años. Desde una mirada retrospectiva, las jornadas de mayo implicaron una derrota de la clase trabajadora, evidenciada por la caída abrupta de la actividad huelguística, la reversión de la estructuración sindical en los sitios laborales y el reflujo de la movilización social. Las organizaciones gremiales quedaron diezmadas, reducidas a su mínima expresión, con sus principales militantes encarcelados o deportados. En el caso del anarquismo, principal foco de la represión, la corriente quedó gravemente dispersa y desorganizada, con sus periódicos prohibidos, e idéntica situación afectó a la FORA. Una primera conclusión, por lo tanto, se refiere a la necesidad de ponderar en el análisis sobre el mundo del trabajo esta clase de episodios de alta conflictividad y represión estatal/paraestatal, cuyos efectos no necesariamente se manifiestan de forma inmediata. Así, junto con otros factores, como la recesión económica de 1913 y el estallido de la Gran Guerra al año siguiente, el movimiento obrero en Argentina no recuperó su dinamismo y organización sino hasta 1916.

En el mundo de la madera, el panorama no fue muy distinto al general, aunque el peso de la derrota impactó de modo desigual en cada sector productivo. En efecto, las diferencias de cualificación entre oficios, así como el diverso grado de contralor sobre el proceso de trabajo plasmaron las fronteras entre universos laborales. El gremio ebanista, por caso, prosiguió una huelga general bajo el estado de sitio y, más aún, logró la obtención parcial de sus propósitos. Al respecto, algunos elementos podrían explicar este conflicto rara avis en el marco de una ofensiva represiva sobre la clase: en primer lugar, el componente del oficio y el alto grado de cualificación en un sector con escasa maquinización, lo cual dificultaba el reemplazo de los huelguistas; en segundo lugar, una férrea trayectoria de estructuración sindical y solidaridad gremial; finalmente, la prolífica intervención de las corrientes de izquierda.

De todas maneras, los ecos de la derrota del Centenario se hicieron sentir con fuerza en los boliches muebleros, donde, al igual que en otras ocasiones de reflujo de la actividad, se reimplantó el destajo, se rebajaron los jornales, se vulneró la jornada de ocho horas y se despidió a los activistas. Entre los escultores en madera, el panorama fue similar. En el subsector carpintero-aserrador, cuya estructuración sindical había recibido un fuerte impulso por parte de la militancia libertaria, la organización quedó en gran parte diluida. A su vez, no era menor el poderío de las patronales, cuya articulación estratégica con el aparato de Estado y la Sociedad Protectora del Trabajo Libre proveía fuerza de trabajo adventicia y medios materiales. Entre estos trabajadores, en contraste con los oficios artesanales, la conflictividad laboral solía emerger de forma concomitante con los ciclos huelguísticos de los obreros portuarios, sosteniendo alianzas temporales entre los estibadores, carpinteros, marineros y carreros.

Con el objetivo de complejizar las relaciones entre los obreros madereros, el artículo indagó las particularidades del sector judío de la industria del mueble de Buenos Aires. En esta dirección, se podría concluir que existió cierta dualidad en el vínculo entre el mundo del trabajo ídish y el resto del ramo: mientras 
que los obreros judíos solían dedicarse a la fabricación de muebles baratos bajo condiciones laborales paupérrimas y en general esquivando las reglamentaciones sindicales, una de las principales fuerzas aglutinantes de los ebanistas era el estatus del oficio y cierta defensa corporativa de la profesión (esto último también se planteó, por ejemplo, entre los constructores de carruajes al momento de enfrentar la descentralización productiva). Sin embargo, la llamada dualidad entre universos laborales no impidió que se coligaran distintos esfuerzos organizativos para atraer a los rusos hacia el sindicato, como una forma de proteger las conquistas. En este punto, podemos afirmar como una segunda conclusión que, si bien existieron tendencias entre los trabajadores judíos hacia una endogamia comunitaria, otras necesidades vinculadas con la lucha gremial promovieron, en cambio, su organización. En cualquier caso, la competencia intertrabajadores resultó una constante durante décadas y, con ella, la posibilidad de que surgiera un sindicato ídish paralelo, como ya ocurría de hecho en otros gremios.

Por último, el análisis sobre la violencia y la represión indicó que, pese a no representar un número demográficamente significativo (frente a otras comunidades, como los italianos o los españoles), los judíos de Buenos Aires llegaron a ocupar un espacio privilegiado en las preocupaciones de la clase dominante. No fue casual, por lo tanto, que uno de los objetivos de la represión del Centenario fueran los rusos del barrio de Once, dando lugar a uno de los primeros pogroms de la historia argentina. Por ende, una tercera conclusión se refiere a que, más allá de que el odio de clase adquirió un cariz xenófobo y antisemita, este último no llegó a cristalizar de modo perdurable y, antes bien, es factible afirmar que, en mayo de 1910, la población judía fue atacada en virtud de un antagonismo social, derivado de la relación fundamental entre capital y trabajo, y como parte de una reacción general sobre la clase obrera, a lo cual se agregó el universo de estereotipos «negativos» que apuntalaba el miedo de la clase dominante. A la inversa, los estereotipos «positivos» fortalecían la solidaridad gremial, como en ocasión de la huelga ebanista judía de 1909.

En síntesis, el artículo se enfocó en un sector productivo específico, analizando un conjunto de dimensiones (conflictividad laboral y social, estructuración sindical y política, relaciones étnicas) con el objetivo de aportar al conocimiento sobre los años formativos de la clase trabajadora de Buenos Aires en un momento crucial de la historia política nacional.

\section{Bibliografía}

BELKIN, Alejandro (2019). Sindicalismo revolucionario y movimiento obrero en la Argentina. De la gestación en el Partido Socialista a la conquista de la FORA (1900-1915). Buenos Aires: Imago Mundi.

BEnARIO, Moisés (1940). «El comercio y la industria judíos de Buenos Aires». En: 50 años del Diario Israelita. Buenos Aires: Comité de Homenaje del Diario Israelita.

BILSKY, Edgardo (1992). «Ethnicité et classe ouvrière: les travailleurs juifs à Buenos Aires (1900-1930)». Le Mouvement Social, París, núm. 159, págs. 39-56. 
BRUSILOVSKY, Enrique (1940). «Los judíos en el movimiento obrero argentino». En: 50 años del Diario Israelita. Buenos Aires: Comité de Homenaje del Diario Israelita. Fuente inédita, traducida al castellano para esta investigación por Lucas Fiszman.

Camarero, Hernán (2007). A la conquista de la clase obrera. Los comunistas y el mundo del trabajo en la Argentina, 1920-1935. Buenos Aires: Siglo XXI.

Censo industrial y comercial de la República Argentina 1908-1914 (1915). Buenos Aires: Talleres Gráficos del Ministerio de Agricultura.

Devoto, Fernando (2007). Historia de la inmigración en la Argentina. Buenos Aires: Sudamericana.

DíAZ, Javier (2016). «El anarquismo en el movimiento obrero judío de Buenos Aires (19051909)». Archivos de Historia del Movimiento Obrero y la Izquierda, Buenos Aires, núm. 8, págs. 119-140.

Dickmann, Enrique (1949). Recuerdos de un militante socialista. Buenos Aires: La Vanguardia.

EVERLEY, Harold E. (1919). «Furniture markets of Argentina, Uruguay, Paraguay and Brazil», USDCBFDC, Special Agents Series, núm. 183, Washington DC, GPO.

FRANCO, Marina (2019). «El estado de excepción a comienzos del siglo xx: de la cuestión obrera a la cuestión nacional». Avances del Cesor, Rosario, núm. 5, págs. 2951.

Frydenberg, Julio y RufFo, Miguel (1992). La Semana Roja de 1909. Buenos Aires: CEAL.

IÑIGo CARRERA, Nicolás (2013). «Aproximación al análisis del Centenario como hito en la confrontación social argentina». PIMSA. Documentos y comunicaciones 2011-2012, Buenos Aires, núm. 14, págs. 69-116.

JONES, Gareth Stedman (2014). Lenguajes de clase. Estudios sobre la historia de la clase obrera inglesa (1832-1982). Madrid: Siglo XXI.

KOPPMANN, Walter L. (2020). «Radiografía sobre la presencia obrera judía en la industria de la madera y del mueble de la ciudad de Buenos Aires, 1894-1921». A Contracorriente: una Revista de Estudios Latinoamericanos, Carolina del Norte, vol. 17, núm. 3, págs. 143-172.

LeWIN, Boleslao (1983). Cómo fue la inmigración judía en la Argentina. Buenos Aires: Plus Ultra.

Lvovich, Daniel (2003). Nacionalismo y antisemitismo en la Argentina. Buenos Aires: Javier Vergara.

MAROTTA, Sebastián (1961). El movimiento sindical argentino. Su génesis y desarrollo, 1907-1920. Buenos Aires: Lacio.

MARX, Karl (2008 [1867]). El capital. Crítica de la economía política, tomo I. Buenos Aires: Siglo XXI.

Mirelman, Victor A. (1988). En búsqueda de una identidad: Los inmigrantes judíos en Buenos Aires, 1890-1930. Buenos Aires: Milá-AMIA.

MonTGOMERY, David (1979). Workers' control in America: studies in the history of work, technology, and labor struggles. Cambridge: Cambridge University Press.

MoYA, José (2004). "The positive side of stereotypes: Jewish anarchists in early-twentieth-century Buenos Aires». Jewish History, núm. 1, págs. 19-48.

RoccHI, Fernando (1994). «La armonía de los opuestos: industria, importaciones y la construcción urbana de Buenos Aires en el período 1880-1920». Entrepasados, Buenos Aires, núm. 7, págs. 43-66. 
SuRIANO, Juan (2001). Anarquistas. Cultura y política libertaria en Buenos Aires, 18901910. Buenos Aires: Manantial.

VISACOVSKY, Nerina (2015). Argentinos, judíos y camaradas. Tras la utopía socialista. Buenos Aires: Biblos.

Fecha de recepción: 1 de junio de 2020

Fecha de aceptación: 7 de octubre de 202

Fecha de publicación: 30 de junio de 2021 